\title{
Blood supply of the ciliary ganglion in the rhesus monkey
}

\author{
M. ELIŠKOVÁ \\ Institute of Anatomy, Medical Faculty, Caroline University, Prague
}

In our study of the central retinal vein in rhesus monkeys (Elišková, I967), we pointed to the problem of drainage of venous blood from the ciliary ganglion into this vein. We noticed the close connexion of the ganglion with the central retinal vein, the main arterial trunks of the orbit (ophthalmic artery, central retinal artery, lateral posterior ciliary artery), and their branches running towards the ganglion.

Little has been published about the ciliary ganglion apart from neuroanatomical and histochemical studies, and studies of the comparative anatomy of the ciliary ganglion and the ciliary nerves (Beauvieux and Dupas, 1926; Winckler, 1932; Kurus, 1956; Grimes and von Sallmann, i96o).

The blood supply of the ciliary ganglion in the human foetus and newborn child has been described by Kuzněcova (1963). Only Hayreh (1964) has mentioned arterial branches running towards the ciliary ganglion in the rhesus monkey; other authors do not deal with this question (Hartman and Straus, r933; Wolff, I948; Weinstein and Hedges, I962; Davson, I962).

It was therefore decided to trace the blood supply to the ciliary ganglion, a structure which is of such importance to vegetative innervation, and to find out whether theoretically there is a possibility of damage to the ganglion in a vascular lesion.

\section{Material and methods}

For the investigation, thirty specimens from rhesus monkeys were used. In fifteen, injection of the arterial network was carried out with a mixture of barium and minium suspended in 7 per cent. gelatin using a cannula introduced into the internal carotid artery, and in another fifteen, the cannula was introduced into the internal jugular vein; here the injection of the venous network was carried out with a suspension of Indian ink in 10 per cent. gelatin after clamping the vein on the other side. How successful the injection of the vascular network had been could be checked by the vessels of the conjunctiva. After the injected material had solidified, the head of the animal was removed and fixed in io per cent. neutral formol. After freeing the upper and lateral walls of the orbit, the retrobulbar space was dissected under a dissecting binocular microscope in order to demonstrate the ciliary ganglion and its vessels.

In three animals marked for histological investigation, perfusion of the cranial vessels with Io per cent. formol was carried out under general anaesthesia, followed by an injection of Indian ink suspended in gelatin and a retrobulbar injection of 10 per cent. formol. After microscopic dissection and description of the findings in situ, the ganglion was removed and investigated in serial histological sections stained with haematoxylin and eosin and Azan; three specimens were cut in a frontal and the other three in a sagittal plane. 
Of the thirty ganglia thus treated, eight (two after arterial injection and six after venous injection) were dehydrated in alcohol and then clarified using methylated benzoan.

\section{Observations}

ARTERIES

The ciliary ganglion lies on the lateral side of the optic nerve and close to the lower cir- $\frac{\mathbb{}}{\circ}$ cumference of the ophthalmic artery trunk (Fig. IA, B). On its medial side run the central retinal artery and the lateral posterior ciliary artery, in six specimens originating. from a common trunk. The lateral posterior ciliary artery touches the medial surface of $\vec{\omega}$ the anterior pole of the ganglion; thence it joins the short ciliary nerves and branches offo into the short posterior ciliary arteries proper. On the lateral side of the ganglion, minute arteries up to a calibre of $0.2 \mathrm{~mm}$. in diameter may be found which branch off into the retrobulbar fat and connective tissue. In other specimens, we found muscle branches of the rectus lateralis or branches linking up with the plexus around the optic nerve. TheyJ్ originated either from the intracanalicular part or the beginning of the intraorbital part $\mathrm{O}$ of the ophthalmic artery. In four specimens, antero-posterior anastomoses with the lateral posterior ciliary artery had thus formed.

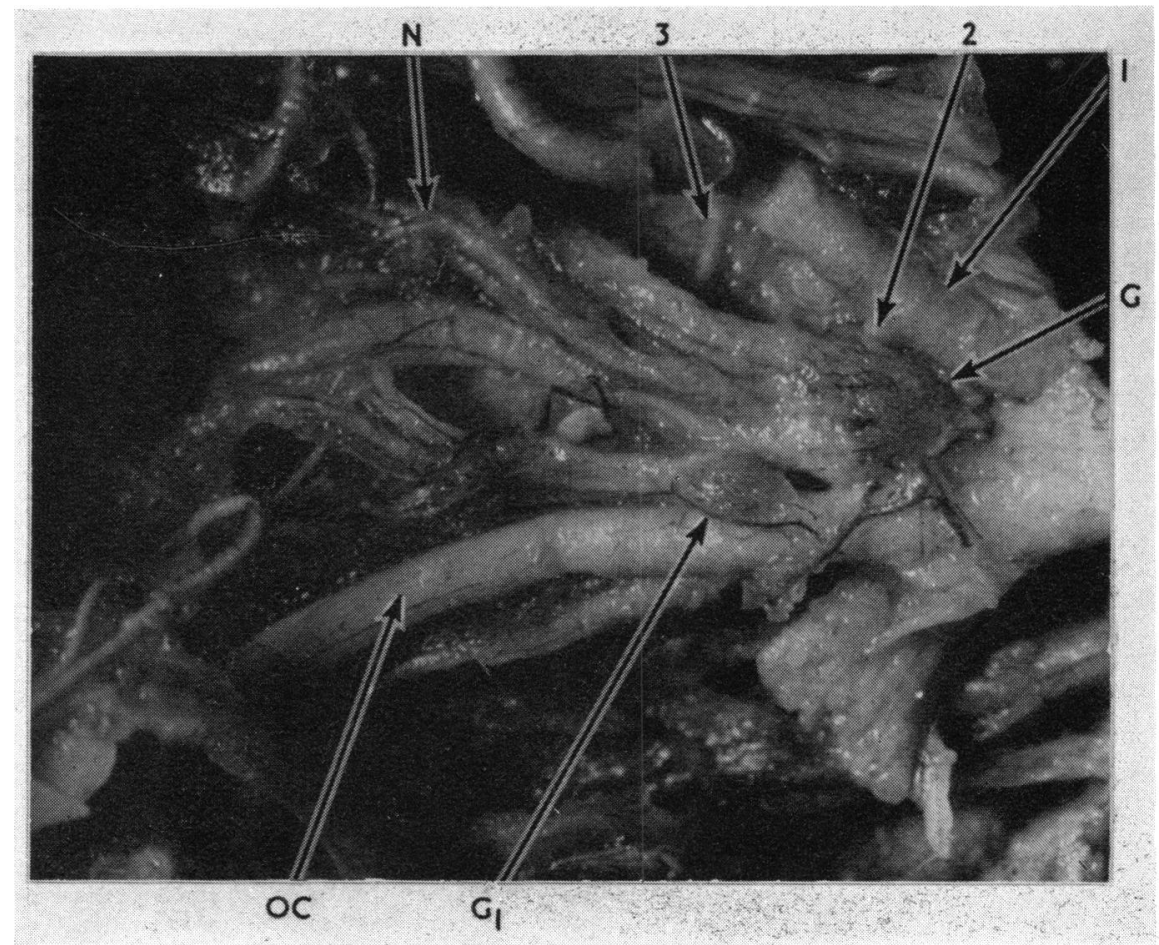

FIG. I (A) Left eye. Situation of ciliary ganglion in retrobulbar space in rhesus monkey. Near the inferior branch of the oculomotor nerve, an accessory ciliary ganglion can be seen. Vessels stained by injection

G - ciliary ganglion

$G_{1}$ - accessory ciliary ganglion

OC - oculomotor nerve

$\mathrm{N}$ - short ciliary nerves
I - ophthalmic artery

2 - central retinal artery

3 - lateral posterior ciliary artery 


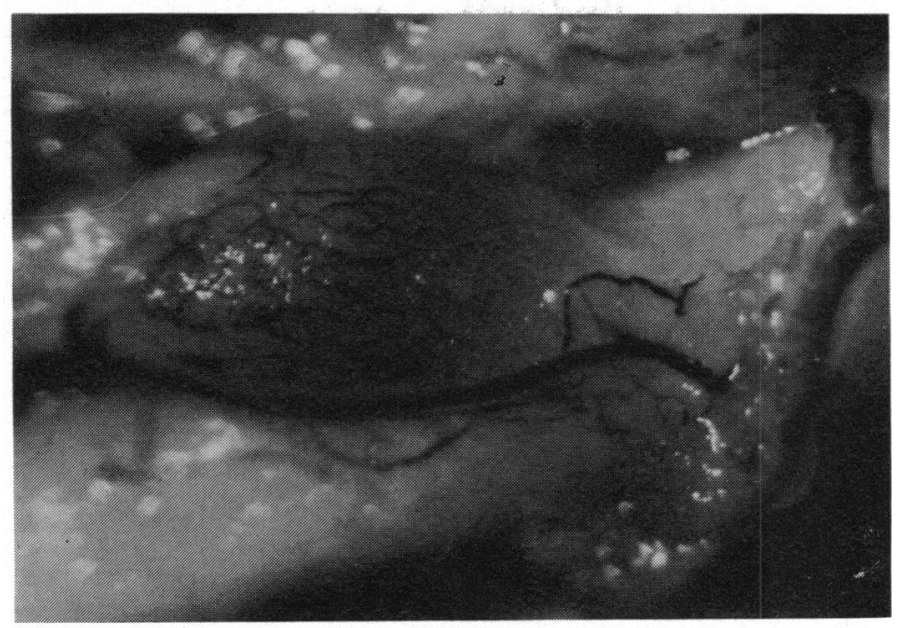

FIG. I (B) Detail of Fig. I (A), showing accessory ciliary ganglion with capillary network converging into veins

Blood to the ciliary ganglion is supplied by the arteries in its neighbourhood (Fig. 2). These are the intracanalicular and intraorbital branches of the ophthalmic artery, branches of the central retinal artery, the lateral posterior ciliary artery, or the common trunk of both these arteries, less frequently also branches of the rami musculares or the lacrimal artery. As can be seen from the Table (overleaf), every ganglion may have one to three main arterial sources. These small arteries often divide into two to four branches about $0.03 \mathrm{~mm}$. in diameter which enter the ciliary ganglion independently at different sites.

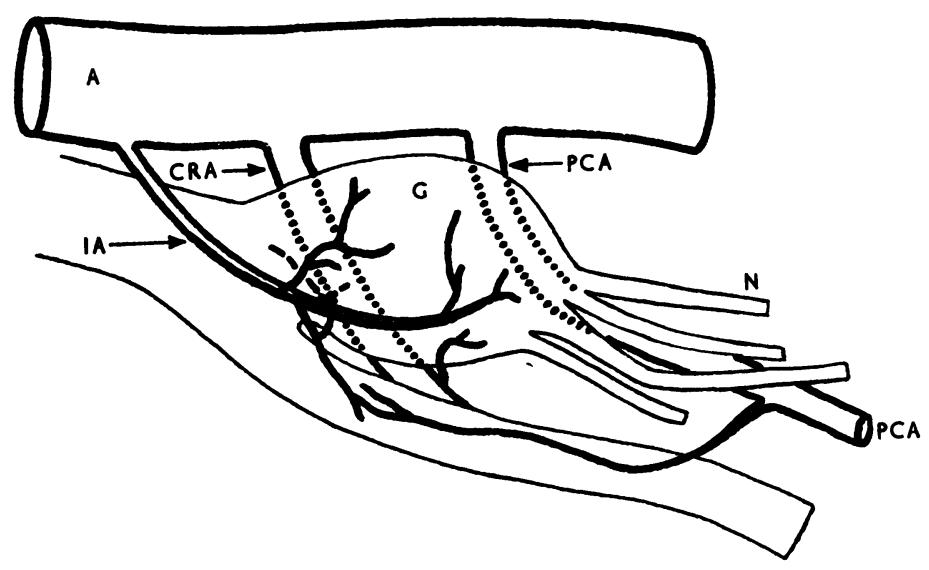

FIG. 2 Diagram of arterial blood supply to ciliary ganglion in rhesus monkey

A - ophthalmic artery

G - ciliary ganglion

$\mathrm{N}$ - short ciliary nerves

CRA - central retinal artery

PCA - lateral posterior ciliary artery

IA - intracanalicular branch of the ophthalmic artery

The areas of the ganglion supplied by certain arteries cannot be limited with precision. Generally, it can be said that the branches of the lateral posterior ciliary artery and the central retinal artery enter the anterior half, while the intracanalicular branches of the ophthalmic artery supply the posterior half of the ganglion. The destination of the intraorbital branches depends on their level of origin from the ophthalmic artery; those originating more dorsally frequently enter the posterior part of the ganglion. The arteries reaching the ganglion from under its capsule branch off into rami which then invade the parenchyma of the ganglion.

The vascular bed proper is formed by a capillary network, the meshes of which are mainly oriented in a sagittal plane, i.e. parallel to the ganglion, and skirt every single 
Table Origin and number of arterial branches supplying the ciliary ganglion in fifteen specimens

\begin{tabular}{|c|c|c|c|c|c|c|c|}
\hline $\begin{array}{l}\text { Specimen } \\
\text { no. }\end{array}$ & $\begin{array}{l}\text { Intraorbital } \\
\text { ophthalmic } \\
\text { artery }\end{array}$ & $\begin{array}{l}\text { Intracanali- } \\
\text { cular } \\
\text { ophthalmic } \\
\text { artery }\end{array}$ & $\begin{array}{l}\text { Lateral } \\
\text { posterior } \\
\text { ciliary } \\
\text { artery } \\
(C P L A)\end{array}$ & $\begin{array}{l}\text { Central } \\
\text { retinal } \\
\text { artery } \\
(C R A)\end{array}$ & $\begin{array}{l}\text { Common } \\
\text { trunk of } \\
C P L A+C R A\end{array}$ & $\begin{array}{l}\text { Muscle } \\
\text { branch }\end{array}$ & $\begin{array}{l}\text { Lacrimal } \\
\text { artery }\end{array}$ \\
\hline I & & 2 & & & 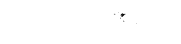 & & \\
\hline 2 & I & & I & : & & & \\
\hline 3 & I & & & $\mathbf{I}$ & & & I \\
\hline 4 & 2 & & & I & & & \\
\hline 5 & & & & & I & & \\
\hline 6 & & & 2 & & 3 & & \\
\hline 7 & 3 & & & & & & \\
\hline 8 & & 3 & I & & & & \\
\hline 9 & I & & & & & 3 & \\
\hline 10 & 4 & & & & & & \\
\hline I I & 4 & & & & & & \\
\hline 12 & 4 & & & & & & \\
\hline I3 & & & I & 3 & & & \\
\hline 14 & 2 & & & & & 2 & \\
\hline I 5 & I & 2 & & & & & \\
\hline
\end{tabular}

ganglion cell in the pattern of an irregular polygon. This network was well seen in serial sections cut in a sagittal plane (Fig. 3).

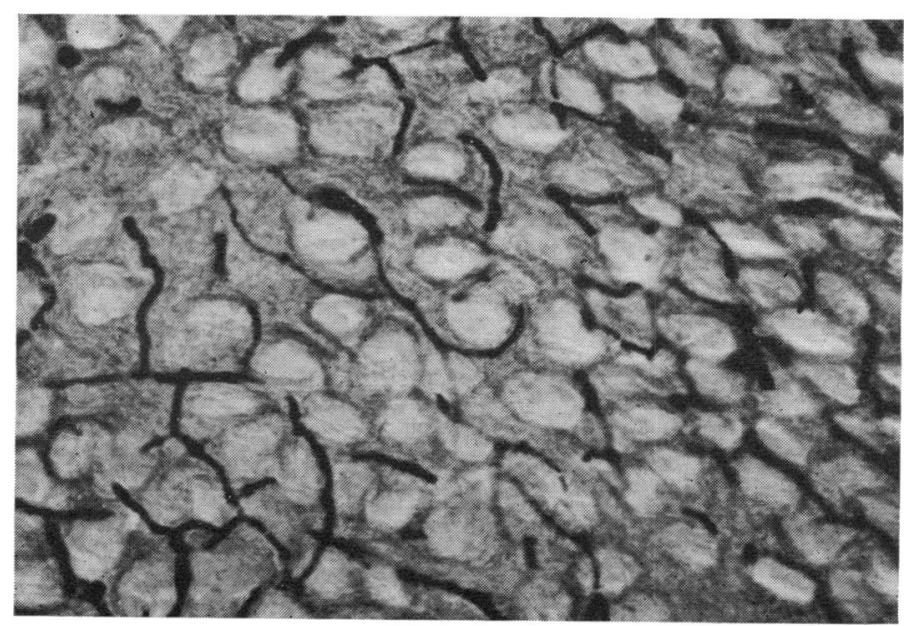

F IG. 3 Section of ciliary ganglion in rhesus monkey cut in a sagittal plane, showing flat network of capillaries skirting each ganglion cell. $\times 125$

Sections cut in the frontal plane, on the contrary, cut across the capillaries (Fig. 4, opposite). 


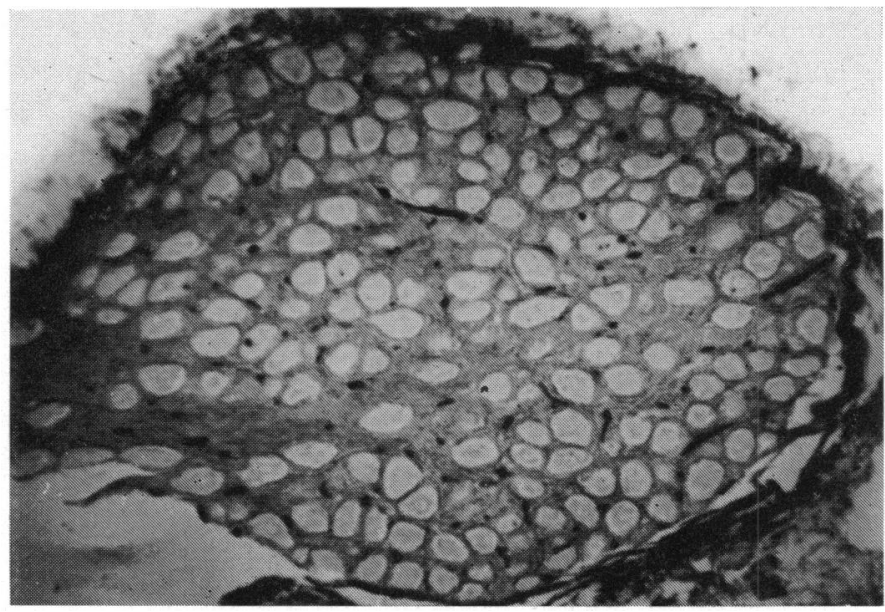

FIG. 4 Section of ciliary ganglion in rhesus monkey cut in frontal plane, showing capillaries cut across. $\times 40$

VEINS

The venous routes draining the blood from the ciliary ganglion are numerous (Fig. 5). Four to eight veins up to $0.05 \mathrm{~mm}$. in diameter leave the ganglion, join each other on its surface, where they usually form asteroids or trees, rapidly enlarge and, after a short course, open into one of the larger venous trunks. This is usually the central retinal vein (in 65.2 per cent.), but may be one of the veins coming from the lateral rectus, the accessory lateral rectus, or the inferior rectus. The central retinal vein, because of its course and close relationship to the ganglion, is the most suitable route for blood draining from it. After its exit from the optic nerve, the vein reaches the anterior pole of the ganglion, there receiving a number of little veins varying from one to seven. Thence the blood drains into the main veins of the orbit, i.e. the superior or inferior ophthalmic vein (Elišková, 1967). Only 12:3 per cent. of veins coming from the ganglion flow directly into one of the ophthalmic veins. The central retinal vein, therefore, is not the only vessel draining blood from the ciliary ganglion; in every specimen, we found at least one branch which would open into some of the other veins mentioned above.

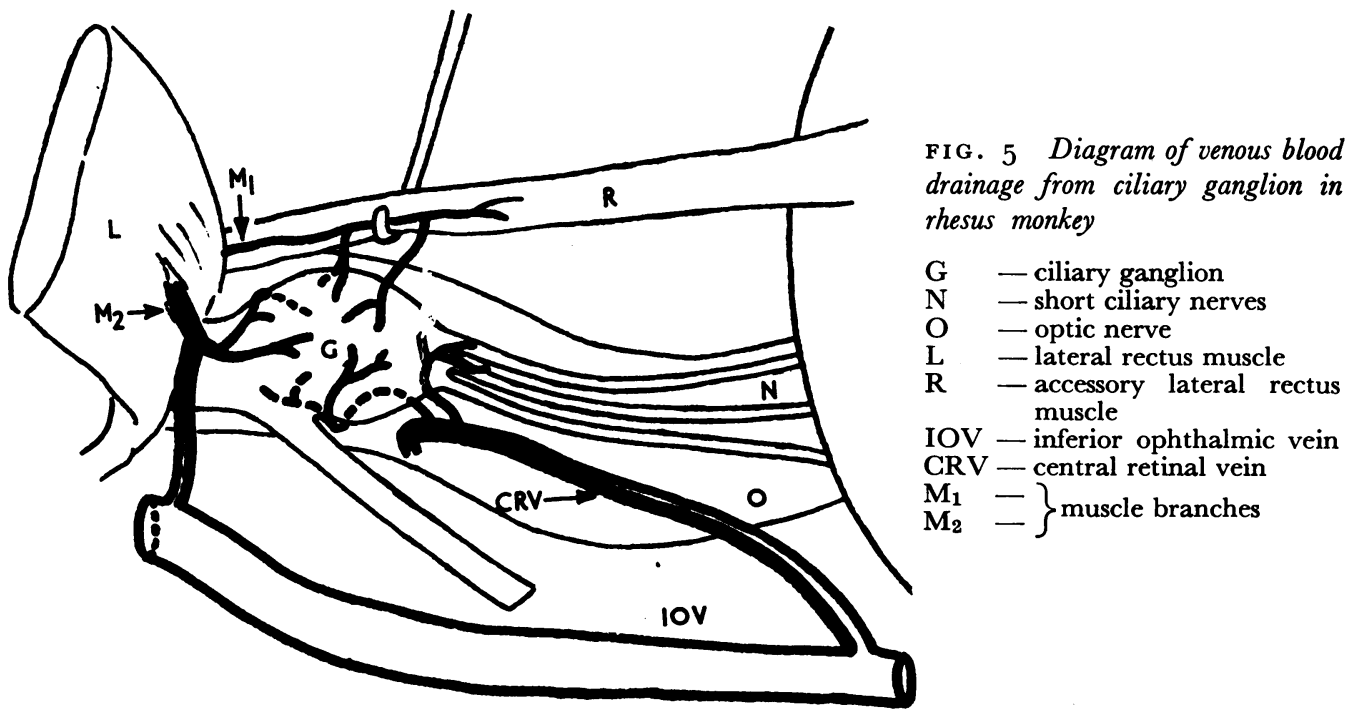

FIG. 5 Diagram of venous blood drainage from ciliary ganglion in as monkey

- ciliary ganglion

O - optic nerve

$\mathrm{L} \quad$ - lateral rectus muscle

muscle

GRV - central retinal vein

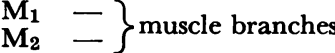


As with the entrance of the arteries, we were unable to find any typical sites of exit for

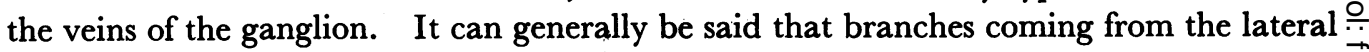
and medial planes run towards the margin, the vessels from the anterior and posterior pole $\overrightarrow{\bar{F}}$ leaving the ganglion at these sites. Around the ganglion, there is a venous network with numerous anastomoses which ensure good drainage of blood from it (Fig. 6).

$6 \mathrm{~A}$

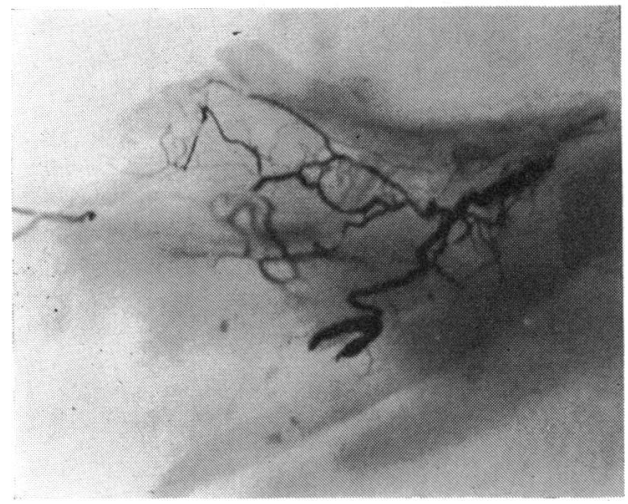

$6 \mathbf{B}$

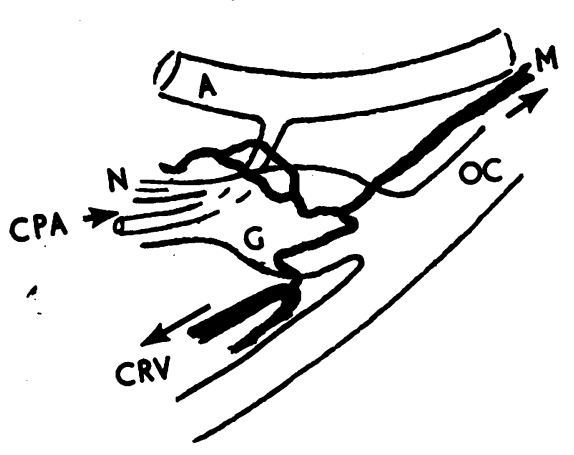

FIG. 6 Photograph (A) and diagram (в) of venous blood drainage from area of ciliary ganglion in clarified $\frac{\Phi}{3}$ section

G - ciliary ganglion

OC- oculomotor nerve

$\mathrm{N}$ - short ciliary nerves

A - ophthalmic artery
CPA - lateral posterior ciliary artery

CRV - central retinal vein emerging from optic nerve

M - muscular branch

\section{Discussion}

Because the ciliary ganglion is situated in the retrobulbar space, it is in close relationship to the large arteries and veins of the orbit. The relationship has been commented $\stackrel{\mathcal{Q}}{\Rightarrow}$ upon by Beauvieux and Dupas (1926) and more recently by Kurz (1956). In their study of regional anatomy, these authors noted the arteries which might touch the ciliary ganglion on its medial plane, but did not mention its blood supply. Our investi-? gations show that there are no constant arteries and that the ciliary ganglion is supplied $\frac{0}{0}$. with blood by occasional vessels branching off from neighbouring arteries. Kuzněcova: ( 1963 ) referred to the small branches originating from the trunk of the ophthalmic artery. and from the short posterior ciliary arteries as the source of the arterial blood supply to the ganglion in the foetus and newborn child. Hayreh (1964), describing the branches of 0 the ophthalmic artery in the rhesus monkey, said that occasional branches might originate from the intracanalicular part of this artery and from the lateral posterior ciliary arteryo and run towards the ciliary ganglion. In our specimens, we also observed little vesselsNo branching off the origin of the central retinal artery, the common trunk of the central retinal and lateral posterior ciliary artery, the lacrimal artery, and the muscle branches. N

The arteries supplying the ciliary ganglion are very small $\left(0.03 \mathrm{~mm}\right.$. in diameter), and ${ }_{\sigma}^{\omega}$ much depends on the technique of injection to fill all branches properly. For histologicalo processing, we preferred to use gelatin with Indian ink, because the mixture fills the vascular network evenly.

In view of the large scatter of supplying arteries, the blood supply of the ciliary ganglion $\frac{0}{0}$ could only be cut off if the vascular lesion were situated above the origin of all branches of the ophthalmic artery. Raitta (1968) reported a patient in whom a saccular aneurysm $\frac{\mathbb{Q}}{\AA}$ was found in the ophthalmic artery which widened the central canal of the optic nerve.으 
The clinical picture was that of optic nerve atrophy, but direct pupillary reaction to light was reduced on the affected side.

This reduction of the pupillary reaction to light may be explained by a disorder in the parasympathetic fibres of the oculomotor nerve (Kurz, 1956) and the ciliary ganglion. The aneurysm situated in the central canal could have pressed on the optic nerve, or on the trunk of the ophthalmic artery, but chiefly on the latter's intracanalicular branches running to the ciliary ganglion. This may have led to ischaemia of the ganglion and through it to the reduction of pupillary reaction to light.

In contradistinction to the above, an aneurysm of the ophthalmic artery situated retrobulbarly in the intraorbital space, as described by Rubinstein, Wilson, and Levin (1968), need not cause any signs of a vascular lesion or disorder in vegetative innervation.

\section{Conclusion}

In thirty specimens from rhesus monkeys, the blood supply of the ciliary ganglion was examined after staining the vascular network by intra-arterial and intravenous injections. The ganglion was seen to be in close relationship to the main arterial trunks of the orbit; the arteries entering it originate from the ophthalmic artery, the lateral posterior ciliary artery, the central retinal artery, the common trunk of both these arteries, and occasionally from muscle branches or the lacrimal artery. Each ganglion may thus be supplied by one to three sources. The supply areas of the different arteries are not precisely limited.

The vascular bed proper of the ciliary ganglion is formed by a capillary network with meshes oriented in the sagittal plane, i.e. parallel to the plane of the organ. The veins, converging in a tree-like fashion on the surface of the ganglion, usually (in 65.2 per cent. of cases) drain the blood into the central retinal vein, but may also drain into the muscle branches or directly into the ophthalmic vein. There is a network of veins around the ganglion, ensuring the drainage of blood.

Reduction of the direct pupillary reaction to light in the presence of an aneurysm of the ophthalmic artery in the optic canal, described in the literature, may be explained also by a lesion of the intracanalicular branch of this artery leading to partial ischaemia of the ciliary ganglion.

\section{References}

BeauvieuX, and dupas, J. (1926) Arch. Ophtal. (Paris), 43, 641

DAvson, H. (1962) “The Eye". Academic Press, New York and London

ELIŠKovÁ, M. (1967) Folia morphol. (Praha), 15, 206

GRIMES, P., and SAllmanN, L. vON (1960) Arch. Ophthal. (Chicago), 64, 8I

hartman, c. G., and straus, w. L. (1933) "The Anatomy of the Rhesus Monkey". Baillière,

Tindall and Cox, London

HAYREH, s. s. (1964) Exp. Eye Res., 3, 16

KURUS, E. (1956) Klin. Mbl. Augenheilk., 129, 183

KURz, J. (1956) “Ofthalmo-neurologická diagnostika". Prague

kUzNecova, L. v. "Blood Supply of the Ciliary Ganglion in Human Fetuses and Newborns", in

“Trudy 6. nauenoj konferencii po vozrastnoj morfologii, fiziologii i biochimii, Moskva 1963", pp. 106-107.

RAITtA, c. (1968) Brit. F. Ophthal., 52, 707

RUBinstein, M. K., Wilson, G., and LEVIN, D. C. (1968) Arch. Ophthal. (Chicago), 80, 42

WEINSTEIN, J. D., and HEDGES, T. R. (1962) Anat. Rec., 144, 37

WINCKLER, G. (1932) Arch. Anat. (Strasbourg), 14, 301

wolfF, E. (1948) "The Anatomy of the Eye and Orbit", 3rd ed. Lewis, London 